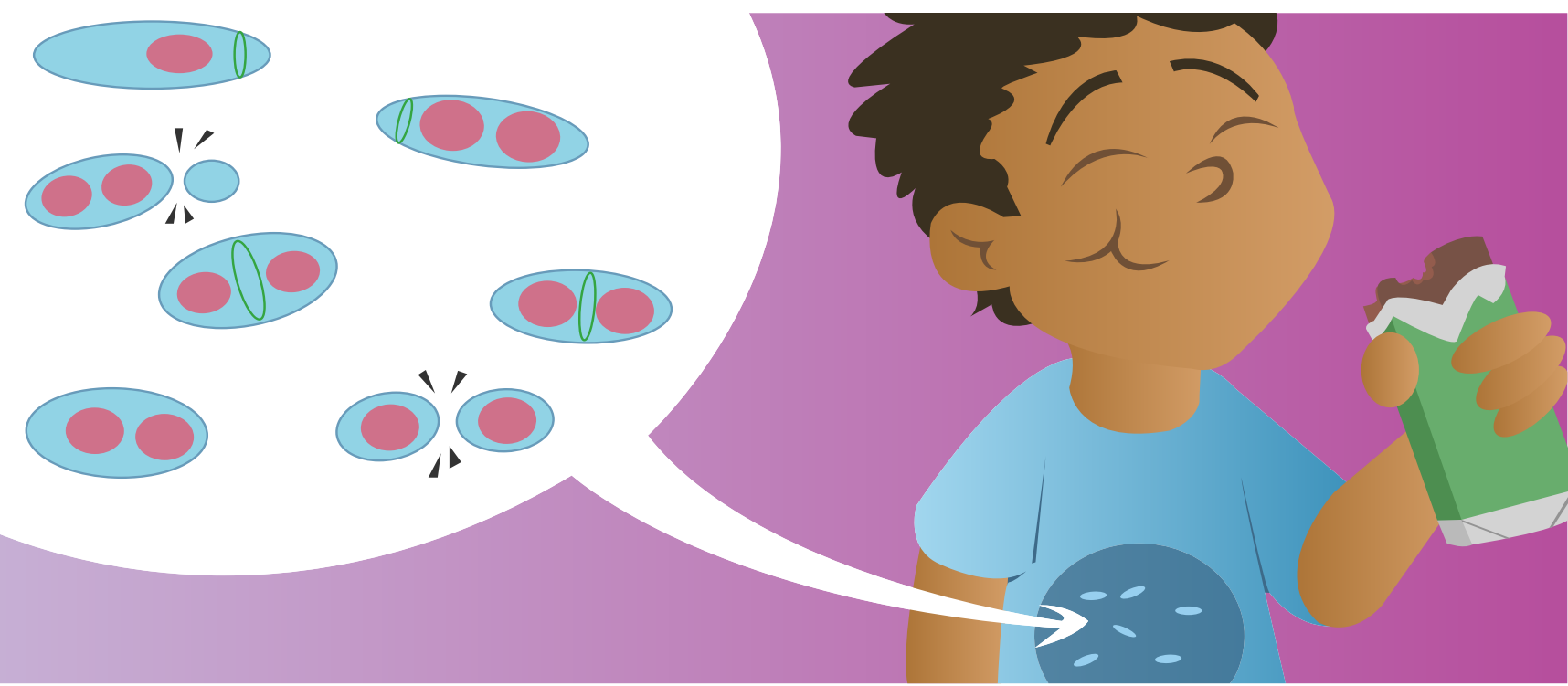

\title{
WE ARE WHAT WE EAT: TRUE FOR BACTERIA TOO
}

\section{Riti Mann, Leigh G. Monahan, Elizabeth J. Harry and Amy L. Bottomley*}

The ithree institute, University of Technology Sydney, Ultimo, NSW, Australia

\section{REVIEWED BY:}

AINE 13 YEARS OLD
Bacteria are present everywhere-all around and within us. Are you scared of them? Do not be, because most bacteria are actually good for us. Only a small number of them can occasionally cause infections, making us sick. Bacteria cause infections by dividing quickly inside the human body, that is, by the process of one cell dividing into two cells at a fast pace. To fuel growth and division, bacteria need to find their favorite food and be able to process (digest) it correctly. Like humans love to eat candies, one of the favorite food choices of bacteria is the simple sugar called glucose. We have found that when glucose is not processed correctly by bacteria, the bacteria cannot divide properly. We want to understand the link between food processing and cell division in bacteria-especially during infection-so that we can stop the bacteria from dividing, by either supplying them with food they do not like or making them process their favorite foods incorrectly. This will kill the bacteria and prevent them from making us sick.

\section{ARE ALL BACTERIA BAD?}

We always have lots and lots of bacteria around us, as they live almost everywhere-in air, soil, in different parts of our bodies, and even in some of the foods we eat, such as yogurt, cheese, and pickles. But do not worry! Most 
BACTERIAL CELL DIVISION

The process of one bacterial cell splitting into two cells.

\section{DNA}

The code within a cell that carries all of the information needed for a cell to survive. bacteria are good for us. Some live in our digestive systems and help us digest our food, and some live in the environment and produce oxygen so that we can breathe and live on Earth. But unfortunately, a few of these wonderful creatures can sometimes make us sick. This is when we need to see a doctor, who may prescribe medicines to control the infection. But what exactly are these medicines and how do they fight with bacteria? These medicines are called "antibiotics," which means "against the life of bacteria." As their name tells us, antibiotics either kill bacteria or stop them from growing by stopping a specific process from working inside the bacterial cell. When the bacteria stop growing, our bodies can then clear the infection and we feel better.

The development of antibiotics is one of the biggest successes of modern medicine. Antibiotics have saved millions of lives since doctors started using them in the 1940s. Antibiotics have helped humans to have much better lives by successfully treating almost all types of bacterial infections. But like us, bacteria are smart, too! Since the 1940s, bacteria have been developing tactics to overcome the effects of antibiotics, and today we are seeing more and more bacteria that can no longer be killed by antibiotics at all. These have become known as antibiotic-resistant bacteria or "superbugs," and they are a serious threat to the health of people all over the world. If we do not have antibiotics to stop bacterial infections, even something as simple as a small infected cut on the finger could become life-threatening. Therefore, new weapons, in the form of new antibiotics, are needed to treat the infections caused by antibiotic-resistant bacteria. To find new antibiotics, we first need to fully understand the inner workings of the bacterial cell. Our lab focuses on understanding something very important about how bacteria work - the way bacteria become two cells from one cell, also called the process of bacterial cell division.

\section{THE BACTERIAL WAY TO BECOME TWO FROM ONE}

Like all kinds of organisms, all bacteria need to grow and multiply to survive as a species. When sufficient food is available, bacteria multiply quickly by doubling in size and then splitting in half, to create two new cells [1]. This is the process of "division" shown in Figure 1A. Bacteria use a kind of machinery inside the cell to do this, which is known as a $\mathrm{Z}$ ring (green ring in Figure 1). The $\mathrm{Z}$ ring forms exactly at the middle of the cell and wraps around the cell. When the cell divides, this creates two new cells that are the same size. During division, everything inside the cell needs to be copied and equally shared between the two new cells. This includes bacterial DNA (shown as brown blobs inside the cell in Figure 1), which is like a code for bacteria that carries all the information needed for a cell to survive. If new cells do not receive a full copy of this information, they cannot grow properly and will not survive. 


\section{FIGURE 1}

(A) The process of cell division, in which the bacterial cell forms a $Z$ ring in the middle of the cell and splits into two equal cells, both of which survive. (B) If the $Z$ ring forms at a position other than the middle, two unequal cells are produced and the smaller cell is not able to survive because it does not get any DNA. The DNA is shown as brown blobs inside the bacterial cell. This shows that it is important for the $Z$ ring to form in the middle of the cell.

\section{METABOLISM}

All the chemical processes involved in converting food into energy are together called metabolism.

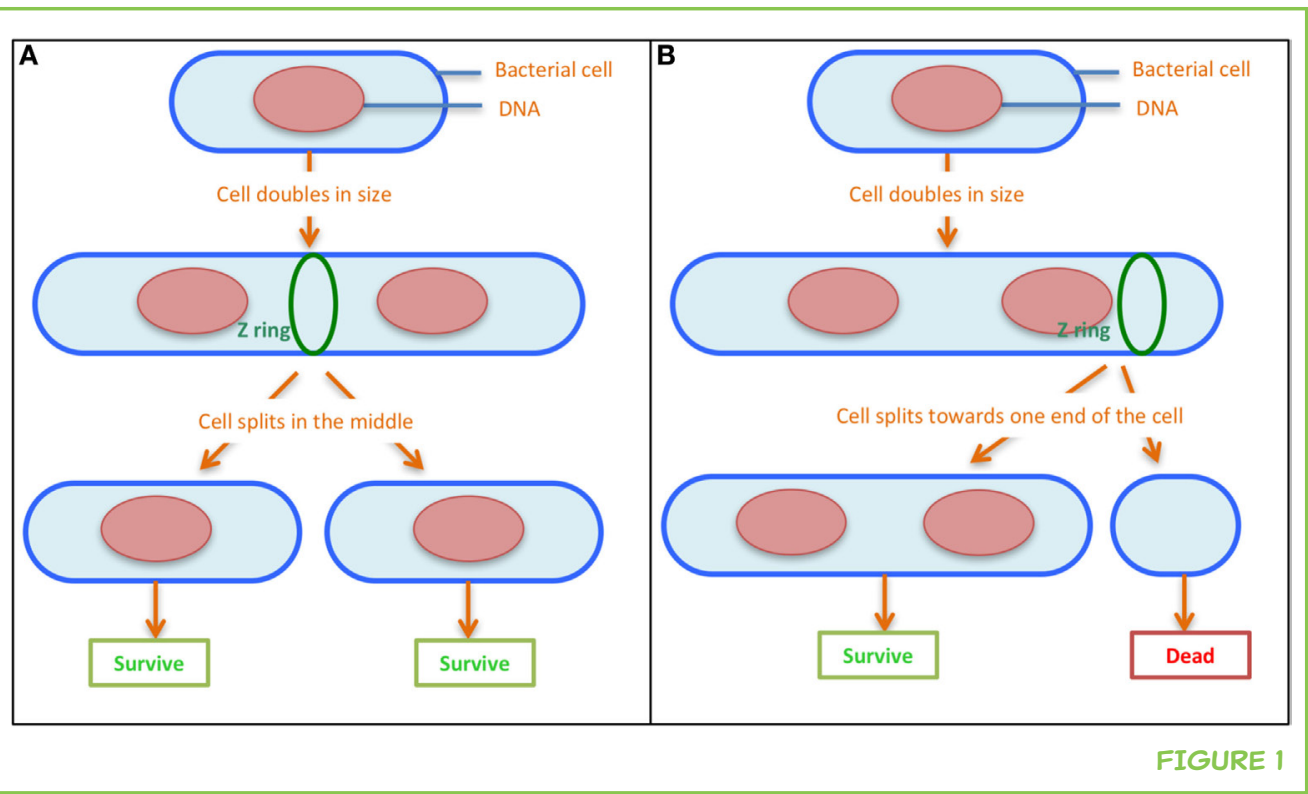

The formation of the $\mathrm{Z}$ ring at exactly the middle of the cell is essential to produce two healthy cells; otherwise one cell will not contain DNA and will die (Figure 1B). This results in only half of the new bacterial cells surviving, which is not so good for bacterial growth. Here comes a very interesting question-how does a bacterial cell make sure that the $\mathrm{Z}$ ring forms only in the middle of the cell and not anywhere else in the cell? The place where the $\mathrm{Z}$ ring forms is so important that it is under the control of many systems [2] that work together to stop the $\mathrm{Z}$ ring from forming anywhere other than the middle of the cell.

In addition to making sure that the $\mathrm{Z}$ ring forms at the right place, a cell also needs to sense the correct time to form the $\mathrm{Z}$ ring and to divide. This depends very much on the environment that the bacteria are in. For example, if it is extremely cold or if there is no food around, bacteria grow very slowly and do not need to divide very often. A good time for bacteria to divide is when plenty of their favorite foods, such as simple sugars, are available. In this situation, the bacterial cells will grow faster and will begin dividing very quickly, to make sure that as many new bacteria as possible are produced before the food runs out. But the question is-how do the bacteria sense the presence of food in its environment and use this information to speed up growth and cell division? This is the question we wanted to answer in our study.

\section{OUR STUDY-BACTERIAL FOOD IS NOT SIMPLY FOR ENERGY, IT DOES MORE.....}

Food is broken down inside a cell to make energy and building blocks for the cell to grow, and the process that does this is known as metabolism. So, in 


\section{ENZYME}

A biological component that helps a reaction to happen quickly.

\section{GLUCOSE}

A simple sugar.

\section{GLYCOLYSIS}

A pathway that breaks glucose into two molecules of pyruvate.

\section{PYRUVATE}

A chemical compound produced after glucose is broken down

(metabolized).

\section{FIGURE 2}

(A) Glucose is made into pyruvate through a pathway called glycolysis, which generates energy and building blocks for the cell. (B) Normal bacteria form $Z$ rings in the middle of the cell, to produce two healthy new cells after division. (C) Cells lacking the enzyme involved in last step of glycolysis form $Z$ rings toward one end of the cell (pointed using the white arrow), resulting in one healthy cell and one small cell that cannot survive because it has no DNA. (D) When pyruvate is added to these cells, they start forming $Z$ rings in the middle again, so the division process works just like that of a normal bacterial cell. other words, the question that we asked in our study was: how is metabolism connected to cell division in bacteria? First, we need to tell you a little bit about how metabolism works. Enzymes are tiny components inside cells that carry out all the chemical reactions required for breaking down food during metabolism. Glucose, which is a simple sugar that comes from the food that bacteria eat, is broken down by enzymes in a number of steps, which together are known as the process of glycolysis (orange box in Figure 2A). The last step of glycolysis produces a compound called pyruvate that is used to generate energy and building blocks for the cell to grow.

As we told you before, a healthy bacterial cell forms a $\mathrm{Z}$ ring in the middle of the cell (Figure 2B). In our study, we have found that, if the enzyme that performs the last step of glycolysis is missing (meaning bacteria are no longer processing their food correctly), the bacterial cell starts forming the $\mathrm{Z}$ ring at locations other than the middle. As you can see in Figure 2C, cells lacking the enzyme involved in the last step of glycolysis form $\mathrm{Z}$ rings toward one end of the cell. This is bad news, and these cells divide incorrectly, producing one big cell and another very small cell that does not contain any DNA, and so can no longer survive. This result showed us that this last step of glycolysis is very important for the correct positioning of the $\mathrm{Z}$ ring at the middle of the cell.

We then wondered if this change in the position of the $\mathrm{Z}$ ring happens because the enzyme involved in the last step of glycolysis is missing, or because the compound produced by this enzyme, pyruvate, is missing? (see Figure 2A). We tested this possibility by removing the enzyme, so that bacterial cells could no longer produce pyruvate themselves, and then we added pyruvate as part of the bacteria's food source. Normally, cells lacking

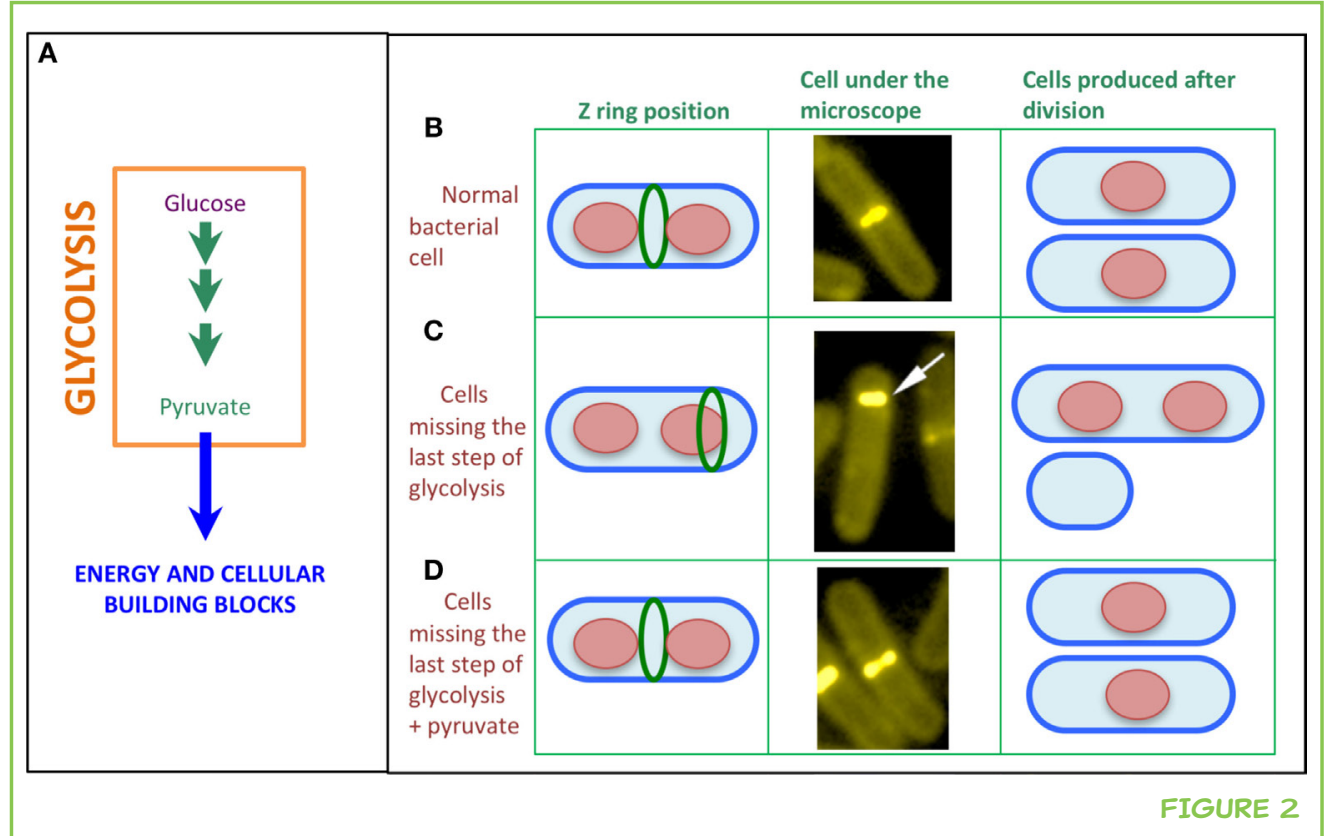




\section{FIGURE 3}

The enzyme that uses pyruvate is found at the same place as bacterial DNA in normal bacteria, which helps the Z ring to form in the middle of the cell. In bacteria that are missing the enzyme involved in the last step of glycolysis, the enzyme that uses pyruvate is found toward the ends of the cell, and that shifts $Z$ ring to form at these places, resulting in a small, unhealthy cell. When pyruvate is added back to these cells, the enzyme comes back to its normal place, which is at the same place as the bacterial DNA, and again it helps the $\mathbf{Z}$ ring to form in the middle of the cell. (Brown blobs represent bacterial DNA, and green blobs represent the enzyme that uses pyruvate to produce energy for the cell.) the enzyme that creates pyruvate form $\mathrm{Z}$ rings toward the ends of the cells, but when pyruvate was added again, the bacteria started forming the $\mathrm{Z}$ rings in the middle of the cell, like healthy bacterial cells do. Have a look at the different positions of $\mathrm{Z}$ rings in cells lacking the enzyme involved in the last step of glycolysis and when pyruvate is added back to these cells, in Figures 2C,D. This result confirmed that it is not the enzyme itself that is important for the position of the $\mathrm{Z}$ ring, but its product-pyruvate. This was the first time that a link between a chemical involved in glycolysis and cell division had been shown, and so pyruvate then became the focus of our further experiments.

\section{HOW DOES THE AVAILABILITY OF FOOD DECIDE THE Z RING POSITION?}

With the finding that pyruvate is important for $\mathrm{Z}$ ring formation in the middle of the cell, we became even more curious to understand how the processes of metabolism and cell division communicate. We know that when pyruvate is produced, it then gets used by another enzyme to produce energy in the cell. We wondered if this second enzyme was located in a certain place inside a bacterial cell, which helps the $\mathrm{Z}$ ring form in the middle.

By making both the DNA and enzyme "glow," we can see where they are located inside the cell using a microscope. In healthy bacteria, we found that the enzyme and DNA were located in the same place, where they both could be seen as round blobs inside the cell (Figure 3 ). In cells that could not produce pyruvate, we found that the enzyme was no longer present at the same place as the DNA, instead the enzyme moved toward the two ends of the cell. This is the same place where $\mathrm{Z}$ rings form in the cells that do not

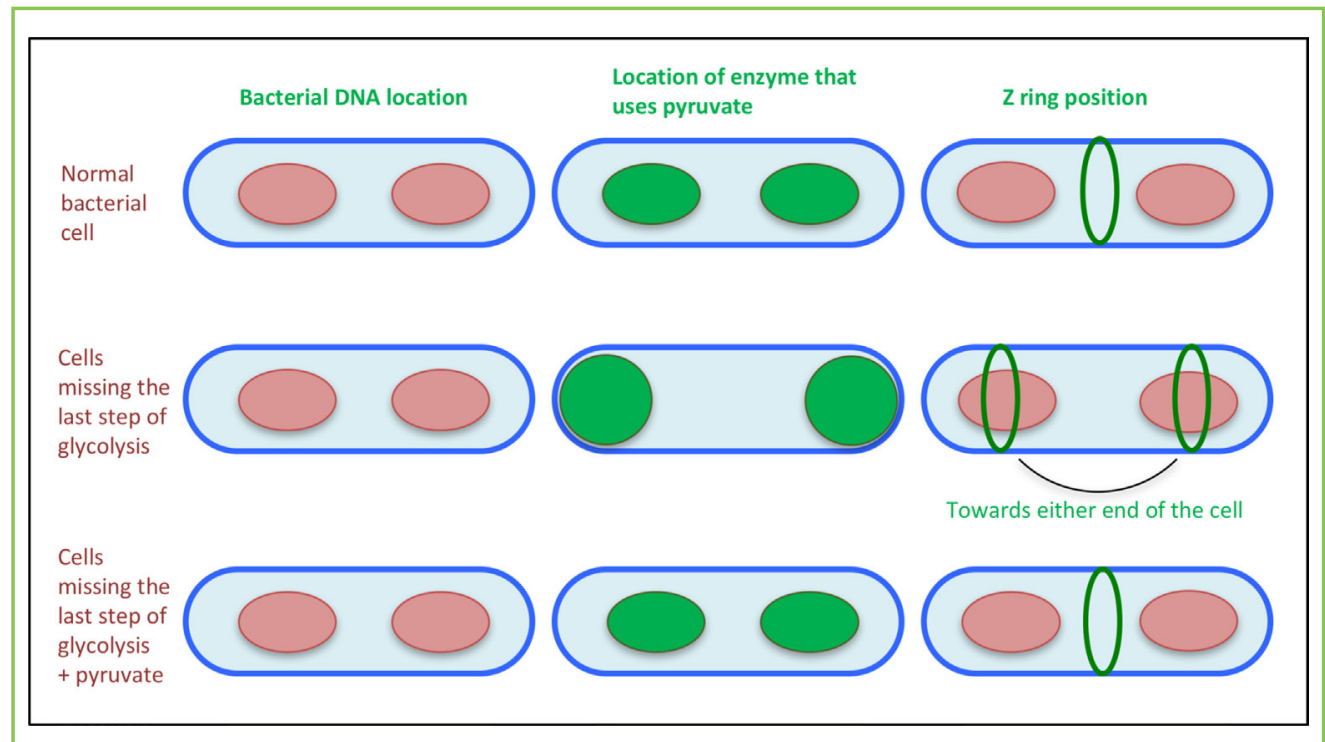

FIGURE 3 
divide properly. We already know that adding pyruvate to these cells shifts the $\mathrm{Z}$ ring back to the middle of the cell again, so we wondered if pyruvate would also change the location of enzyme back to where the DNA was found. This is exactly what happened! These results showed that pyruvate is important for the correct positioning of the $\mathrm{Z}$ ring in the middle of the cell, and pyruvate does this somehow by working with the enzyme that uses pyruvate to make energy. This makes sense, because pyruvate and the enzyme work together in the same pathway.

Our results showed that metabolism and bacterial cell division communicate with each other through pyruvate (and the enzyme that uses pyruvate to produce energy) to ensure the $\mathrm{Z}$ ring forms in the right place. In well-fed bacteria (that can properly make pyruvate), the enzyme is located in the same place as DNA in the cell. At this location, the enzyme seems to help the $\mathrm{Z}$ ring form in the middle of the cell, so the cell divides correctly. However, if cells do not make pyruvate, the enzyme ends up in the wrong place and so does the $\mathrm{Z}$ ring (toward to ends of the cell). So, when food is not processed correctly and pyruvate is not produced, bacteria start to make mistakes in the cell division process. This is similar to what is seen in people with lactose intolerance. When they drink milk, they cannot process lactose properly and therefore become sick. So, the ability to correctly process food and be healthy is really important for all living things. When food is not processed the way it should be in bacteria, the $\mathrm{Z}$ ring is formed at locations where it should not be, which makes cells divide the wrong way, reducing the number of bacteria chance of the bacterial population surviving. This mistake in division can be fixed by giving bacteria the correct food (adding back pyruvate), showing that the way bacteria use the food in their environment is critical for their ability to grow and divide.

\section{WHY DO WE CARE ABOUT THE METABOLISM- DIVISION LINK?}

The question we asked in this study was: how do bacteria sense food availability in the environment and how does the presence of food affect the process of cell division? When food is easy to find, bacteria grow and divide very quickly, but they divide much more slowly when food is scarce. How bacteria know to divide at different rates when different levels of food are around is not known. By understanding more about how bacteria can sense available food sources, especially during infection, and how the sensing of food controls bacterial growth, we can stop bacteria from getting the right type of food or from being able to properly process their food, which can stop them from dividing and prevent them from causing infections. This is because bacteria cannot grow properly if they do not get the right food or if they do not process food correctly. This is similar to humans-we eat good food to stay healthy and not eating the right food can make us sick. 
Therefore, the phrase "we are what we eat" applies equally to bacteria and humans. From this study, we have found an exciting new link between bacterial metabolism and cell division. But these processes are very complex and we have only just scratched the surface to try to understand this link-so the next step will be to solve this mystery.

At the beginning of this article, we talked about the issue of antibiotic resistance. What does the link between metabolism and cell division have to do with antibiotic resistance? To tackle the issue of antibiotic resistance, we need to develop new antibiotics that target unexplored aspects of bacterial growth and survival. Many of the currently available antibiotics target processes that bacteria use to make either DNA, proteins or the outer layer of the bacterial cell. These antibiotics have been very successful, but bacteria have developed tactics to continue doing these processes, even in the presence of antibiotics. In this work, we identified a new link between metabolism and cell division in bacteria, which could serve as a target for new antibiotics. If we could stop bacteria from making pyruvate, or change where the enzyme that uses pyruvate is located within the cell, both metabolism and cell division will be disrupted and cells will die. If an antibiotic can be made that targets two different processes that are important for bacterial survival (metabolism and cell division), it will be more difficult for the bacterial cell to become resistant to that antibiotic, since it will have to develop tactics to overcome the effect of the antibiotic on both of these processes. Making antibiotic resistance much harder for a bacterial cell to achieve will hopefully provide a new solution to combat antibiotic resistance.

\section{ACKNOWLEDGMENTS}

RM is supported by an Australian Government Research Training Program Scholarship. $\mathrm{AB}$ and $\mathrm{EH}$ are supported by an Australian Research Council Discovery project grant DP150102062.

\section{ORIGINAL SOURCE ARTICLE}

Monahan, L. G., Hajduk, I. V., Blaber, S. P., Charles, I. G., and Harry, E. J. 2014. Coordinating bacterial cell division with nutrient availability: a role for glycolysis. MBio 5(3):1-13. doi:10.1128/mBio.00935-14

\section{REFERENCES}

1. Adams, D. W., and Errington, J. 2009. Bacterial cell division: assembly, maintenance and disassembly of the Z ring. Nat. Rev. Microbiol. 7(9):642-53. doi:10.1038/ nrmicro2198 
2. Monahan, L. G., Liew, A. T. F, Bottomley, A. L., and Harry, E. J. 2014. Division site positioning in bacteria: one size does not fit all. Front. Microbiol. 5:1-7. doi:10.3389/fmicb.2014.00019

SUBMITTED: 07 April 2017; ACCEPTED: 08 September 2017; PUBLISHED ONLINE: 29 September 2017.

EDITED BY: Caroline Helen Brennan, Queen Mary University of London, United Kingdom

CITATION: Mann R, Monahan LG, Harry EJ and Bottomley AL (2017) We Are What We Eat: True for Bacteria Too. Front. Young Minds 5:54. doi:10.3389/frym.2017.00054

CONFLICT OF INTEREST STATEMENT: The authors declare that the research was conducted in the absence of any commercial or financial relationships that could be construed as a potential conflict of interest.

COPYRIGHT @ 2017 Mann, Monahan, Harry and Bottomley. This is an open-access article distributed under the terms of the Creative Commons Attribution License (CC BY). The use, distribution or reproduction in other forums is permitted, provided the original author(s) or licensor are credited and that the original publication in this journal is cited, in accordance with accepted academic practice. No use, distribution or reproduction is permitted which does not comply with these terms.

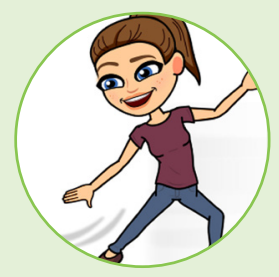

\section{REVIEWED BY}

\section{AINE, 13 YEARS OLD}

My name is Aine, and I am 13 years old. I go to Latymer School in London. I enjoy science especially biology.

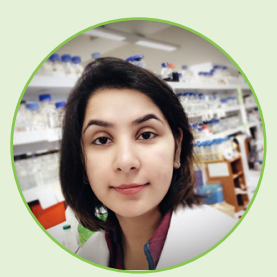

\section{AUTHORS}

\section{RITI MANN}

I am a PhD student at the ithree institute in the University of Technology Sydney, Australia. I am interested in understanding the process of how cell division is controlled in bacteria. The focus of my current work is to know how a bacterial cell communicates information about food availability to its cell division machinery. This will allow the cell division process to be changed according to how much food is available, allowing a cell to divide quickly when lots of food is present and slowly when there is a scarcity of food.

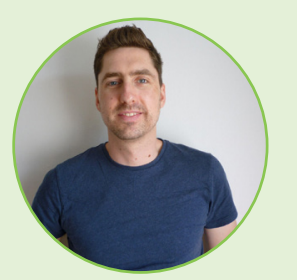

\section{LEIGH G. MONAHAN}

My name is Leigh G. Monahan. I am a microbiologist at the ithree institute in Sydney, Australia. I have studied bacteria for over 10 years now, and I am fascinated with understanding how they grow and multiply, how they adapt to different environments, and how they are able to resist antibiotics that are supposed to kill them! My current research focuses on developing new DNA sequencing technologies that will help us to address some of these questions by investigating the bacterial genetic code. 


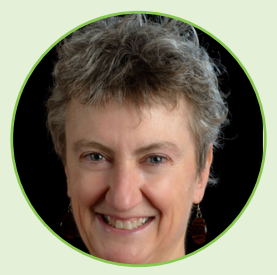

\section{ELIZABETH J. HARRY}

I am interested in understanding how bacterial cells regulate their division. I want to know what signals are needed for cells to divide at the right place and at the right time. I love using microscopy, as it is colorful and I love color and actually seeing things! We can now see the behavior of tiny division molecules inside bacterial cells, to help understand their role in division. I work with companies to identify new ways to treat bacterial infections when they are resistant to our current antibiotics. I am also finding how honey, an "antibiotic" made by bees, works to kill bacteria!

\section{AMY L. BOTTOMLEY}

I am a Scottish microbiologist, who lives and works in Australia. I am interested in how bacteria grow and divide, and how this is regulated in response to different conditions, such as food availability or during infection. I have always been fascinated to learn about the smart ways that tiny bacteria have developed to survive in so many different environments, and I hope my research will contribute to our understanding of how to treat infections. I love living in Australia, especially getting the chance to see so much cool wildlife!

*amy.bottomley@uts.edu.au 